\title{
PARTISIPASI ANGGOTA P3A DALAM PEMELIHARAAN JARINGAN IRIGASI
}

\author{
Lili Afrylia Ibrahim \\ Welson M. Wangke \\ Melsje Y. Memah
}

\begin{abstract}
This study aims to find out the participation of P3A (Farmers of water user Group) farmers in maintaining irrigation networks. The data used in this research is in the form of primary data and secondary data. Primary data obtained by direct observation at the location or interviews based on the questionnaires with members of the P3A Tara-tara Three Urban Village, Sub-district of West Tomohon, Tomohon City. While secondary data including articles related to research. The method of analysis used in this study is the random sampling method means that every member of the population has the same opportunities and opportunities to be selected as a sample. This study suggests that the participation of P3A members in the maintenance of irrigation networks, the areas that run the rice fields from upstream to downstream, so that the benefits of irrigation can be felt maximally. Hence, P3A is required for maximum management and maintenance by using participatory management approach. Basically, participatory irrigation management and maintenance approach is a strategic approach in managing irrigation infrastructure through farmer participation in all aspects of irrigation management, including planning, design, implementation, development (development/rehabilitation), and financing.
\end{abstract}

Keywords: participation, P3A members, maintenance, irrigation network, Urban Village of Taratara Three

\begin{abstract}
ABSTRAK
Penelitian ini bertujuan untuk mengetahui mengetahui partisispasi anggota petani (Perkumpulan Petani Pemakai Air) P3A dalam pemeliharaan jaringan irigasi. Data yang digunakan dalam penelitian ini berbentuk data primer dan data sekunder. Data primer di peroleh pengamatan langsung di lokasi yaitu dari hasil kuesioner atau wawancara dengan anggota P3A Kelurahan Taratara Tiga, Kecamatan Tomohon Barat, Kota Tomohon. Sedangkan data sekunder, dan artikel-artikel yang berhubungan dengan penelitian. Metode analisis yang digunakan dalam penelitian ini adalah metode random sampling (sampe lacak) artinya setiap anggota dari populasi memiliki kesempatan dan peluang yang sama untuk di pilih sebagai sampel. Dan penelitian ini mengemukakan partisipasi anggota P3A dalam pemeliharaan jaringan irigasi, daerah yang mengaliri areal sawah dari hulu hingga hilir, agar manfaat irigasi dapat dirasakan secara maksimal. Maka, dibutuhkanlah P3A (Perkumpuan petani pemakai air) untuk pengelolaan dan pemeliharaan yang maksimal dengan menggunakan pendekatan pengelolaan partisipasioleh P3A Pada dasarnya, pendekatan pengelolaan dan pemeliharaan irigasi partisipatif adalah suatu pendekatan strategis dalam pengelolaan infrastruktur irigasi melalui keikutsertaan petani dalam semua aspek penyelenggaraan irigasi. Termasuk perencanaan, desain, pelaksanaan, pengembangan (pembangunan/rehabilitasi), dan pembiayaan.
\end{abstract}

Kata kunci: partisipasi, anggota P3A, pemeliharaan, jaringan irigasi, Kelurahan Tara-tara Tiga 


\section{PENDAHULUAN}

\section{Latar Belakang}

Indonesia merupakan salah satu negara yang memberikan komitmen tinggi terhadap pembangunan ketahanan pangan sebagai komponen strategis dalam pembangunan nasional. Undang-Undang Nomor 7 Tahun 1996 tentang pangan menyatakan bahwa perwujudan ketahanan pangan merupakan kewajiban pemerintah bersama masyarakat (Partowijoto, 2004). Undang-undang No.50 Tahun 2001. Keputusan menteri dalam negeri tentang pedoman pemberdayaan perkumpulan petani pemakai air (P3A) menteri dalam negeri. Petani Pemakai Air adalah semua petani yang mendapat nikmat dan manfaat secara langsung dari pengelolaan air dan jaringan irigasi termasuk irigasi pompa yang meliputi pemilik sawah, pemilik penggarap sawah, penggarap/penyakap, pemilik kolam ikan yang mendapat air dari jaringan irigasi, dan pemakai air irigasi lainnya, Perkumpulan petani pemakai air yang selanjutnya disingkat P3A adalah istilah umum untuk kelembagaan pengelola irigasi yang menjadi wadah petani pemakai air dalam suatu daerah pelayanan irigasi pada tingkat tersier atau desa yang dibentuk oleh petani sendiri secara demokratis. Dimana partisipasi dapat juga berarti bahwa pembuat keputusan menyarankan kelompok atau masyarakat ikut terlibat dalam bentuk penyampaian saran dan pendapat, barang, keterampilan, bahan dan jasa.Partisipasi dapat juga berarti bahwa kelompok mengenal masalah mereka sendiri, mengkaji pilihan mereka, membuat keputusan, dan memecahkan masalahnya(Tuti, 2003). Irigasi sendiri sangat penting dalam menunjang produksi pertanian dan ketahanan pangan nasional.Kementrian Pekerjaan Umum (PU) dalam membangun dan meningkatkan potensinya.Meski PU diberi kewenangan, di era reformasi ini tentu saja harus ada partispasi masyarakat. Kementrian PU telah mengeluarkan Peraturan Menteri (Permen) terkait pentingnya partisipasi masyarakat dalam pengelolaan irigasi.Diantaranya adalah Permen PU No. 30 tahun 2007 tentang Pedoman Pengembangan dan Pemeiharaan Sistem Irigasi Partisipasi.(Dinas Pertanian Peternakan Perkebunan dan Kehutanan Kota Padang, 2009).

Daerah Irigasi Kelurahan Tara-tara Tiga Kecamatan Tomohon Barat Kota Tomohon telah menjadi saah satu wadah keirigasian dengan di bentuk P3A oleh pemerintah dan disepakati oleh masyarakat yaitu P3A (Ketusaran) dengan jumalah anggota P3A 130 anggota, secara administratif termasuk dalam wilayah pemerintahan Kecamatan tomohon barat dengan luas Daerah Irigasi $25 \mathrm{Ha}$. Daerah irigasi ini mengaliri areal sawah dari hulu hingga hilir. Agar manfaat irigasi dapat dirasakan secara maksimal, maka di butuhkanlah P3A (Perkumpuan petani pemakai air) untuk pengelolaan dan pemeliharaan yang maksimal dengan menggunakan pendekatan pengelolaan partisipasi oleh P3A Pada dasarnya, pendekatan pengelolaan dan pemeliharaan irigasi partisipatif adalah suatu pendekatan strategis dalam pengelolaan infrastruktur irigasi melalui keikutsertaan petani dalam semua aspek penyelenggaraan irigasi, termasuk perencanaan, desain, pelaksanaan, pengembangan (pembangunan/rehabilitasi), dan pembiayaan. Kondisi kelembagaan P3A ketusaran di Kelurahan Tara-Tara Tiga Kecamatan Tomohon Kota Komohon, pada saat ini menghadapai permasalahan salah satunya dari segi aspek keuangan yaitu iuran pengelolaan air yang dibebankan kepada anggota P3A. Anggota P3A tidak tertib dalam pembayaran iuran yang dana tersebut bertujuan untuk biaya pemeliharaan ditingkat tersier yang merupakan kewenangan kelembagaan P3A untuk mengembalikan fungsi jaringan irigasi selain diperlukan pekerjaan rehabilitasi terhadap jaringan yang ada, juga diperlukan perkuatan terhadap kelembagaan pemeliharaan irigasi salah satunya perkumpulan petani pemakai air (P3A).

\section{Rumusan Masalah}

Berdasarkan latar belakang yang menjadi masalah dalam penelitian ini yaitu bagaimana partisipasi anggota petani P3A dalam pemeliharaan jaringan irigasi?

\section{Tujuan Penelitan}

Tujuan untuk mengetahui partisispasi anggota petani P3A dalam pemeliharaan jaringan irigasi.

\section{Manfaat Penelitian}

Partisipasi anggota petani P3A dalam pemeliharaan jaringa irigasi bermanfaat untuk petani agar terjaganya kondisi dan fungsi jaringan irigasi yang telah dibangun.Memberi tambahan informasi kepada pihak yang berkepentingan 
dalam menentukan keputusan dibidang pelaksanaan pemeliharaan sistem irigasi.

\section{METODE PENELITIAN}

\section{Waktu dan Tempat penelitian}

Penelitian ini dilaksanakan selama tiga bulan dari bulan Februari 2017 sampai dengan bulan April 2017 mulai dari persiapan, pengambilan data sampai penyusunan laporan dan ujian akhir. Tempat penelitian di Kelurahan Tara-Tara Tiga Kecamatan Tomohon Barat Kota Tomohon.

\section{Metode pengumpulan Data}

Data yang digunakan dalam penelitian ini berbentuk data primer dan data sekunder, data primer di peroleh pengamatan langsung di lokasi yaitu dari hasil kuesioner atau wawancara dengan anggota P3AKelurahan Tara-tara Tiga kecamatan Tomohon Barat Kota Tomohon.Sedangkan data sekunder.Dan artikelartikel yang berhubungan dengan penelitian.

\section{Metode Pengambilan Sampel}

Pengambilan sampel dalam penelitian ini adalah dari 138 populasi anggota P3A, yang diambil jumlah sampel sebanyak 30 sampel anggota P3Asecara random, dimana randomsampling (sampel acak) artinya setiap anggota dari populasi memiliki kesempatan dan peluang yang sama untuk di pilih sebagai sampel. Tidak ada intervensi tertentu dari peneliti.Masing-masing jenis dari pengambilan acak ini memiliki kelebihan dan kelemahan tersendiri.

\section{Konsep pengukuran Variabel}

Konsep pengukuran ariabel dalam penelitian ini adalah sebagai berikut:

1. Karakteristik responden meliputi : Nama, Jenis Kelamin, Umur, Tingkat pendidikan

2. Partisipasi anggota P3A dalam pemeliharaan jaringan irigasi yaitu dengan partisipasi fisik dan partisipasi non fisik sebagai berikut:

a.) Partisipasi fisik :

1. Melakukan perbaikan bangunan Irigasi yang rusak setiap tahun 2 kalidengan skor.

a. Melakukan perbaikan bangunan yang rusakAktif $=3$ b. Melakukan perbaikan bangunan yang rusak, Kurang aktif = 2

c. Melakukan prbaikan bangunan yang rusak, Tidak aktif $=1$

2. Membersihkan saluran dan bangunan dari tanaman setiap tahun 4 kalidengan skor.

a. Membersihkan saluran dan bangunan dari tanaman liar, Aktif $=3$

b. Membesihkan saluran dan bangunan dari tanaman liar. Kurang aktif $=2$

c. Membersihkan saluran dan bangunan dari tanaman liar. Tidak aktif $=1$

3. Memberisihkan saluara bangunan dari sampah dan kotoran setiap tahun 4 kali dengan skor

a. Membersihkan saluran dan bangunan dari sampah dankotoran, Aktif $=3$

b. Membersihkan saluran dan bangunan dari sampah dan kotoran, Kurang aktif $=2$

c. Membersihkan saluran dan bangunan dari sampah dan kotoran, Tidak aktif $=1$

b.) Partisipasi non fisik :

1. Diwujudkan rapat anggota dalam sumbangan, gagasan dan waktu setiap tahun 4 kalidengan skor.

2. Diwujudkan rapat anggota:

3. Diwujudkan rapat anggota, Aktif $=3$

4. Diwujudkan rapat anggota, Kurang aktif $=$ 2

5. Diwujudkan rapat anggota, Tidak aktif $=$ 1

(1). Dalam bentuk gagasanseperti :

(2). Pendapat

(3). Saran

(4). Hasil rapat

a. Aktif $=3$ b. Kurang aktif $=2 \mathrm{c}$. Tidak aktif $=1$

6. Waktu rapatseperti : (Kehadiran dalam rapat)
a. Aktif $=3$ b. Kurang aktif $=2$
c.

Tidak aktif $=1$

7. Rapat denganpengurus P3A setiap tahun 6 kalidenganskor

a. Rapat dengan penguus P3A, Aktif $=3$

b. Rapat dengan pengurus P3A, Kurang aktif $=2$

c. Rapat dengan pengurus P3A, Tidak aktif $=1$

8. Penyumbangan dan iuran pembiayaan saluran irigasi setiap tahun 12 kali dengan skor

a. keaktifanpenyumbangan dan mengurus pembiayaan saluran irigasi, Aktif $=3$ 
b. keaktifan penyumbangan dan mengurus pembiayaan saluran irigasi, Kurang aktif = 2

c. keaktifan penyumbangan dan mengurus pembiayaan saluran irigasi, Tidak aktif $=1$

Penentuan penilaian partisipasi anggota petani P3A dalam pemeliharaan jaringan irigasi berdasarakan total skor dari masing-masing indicator partisipasi anggota $\mathrm{P} 3 \mathrm{~A}$ sebagai berikut : $17-24=$ Aktif 3

$9-16=$ Kurang Aktif 2

$0-8=$ Tidak Aktif 1

Kemudian diambil penilaian aktif, tidak aktifnya partisipasi anggota petani P3A sebagai berikut :

$481-720=$ Aktif

$31-480=$ Kurang Aktif

$0-30=$ Tidak Aktif

\section{Analisis data}

Data yang diperoleh dari penelitian ini dianalisis secara deskriptif dan disajikan dalam bentuk tabel frekuensi.Tabel frekuensi adalah salah satu bentuk penyajian data yang dibuat agar data yang telah dikumpulkan dalam jumlah yang sangat banyak dapat disajikan dalam bentuk yang jelas dan baik. Dengan kata lain, tabel frekuensi dibuat untuk menyederhanakan bentuk dan jumlah data sehingga ketika disajikan kepada para pembaca dapat dengan mudah dipahami atau dinilai.

\section{HASIL DAN PEMBAHASAN}

\section{Gambaran Umum Lokasi Penelitian}

Kelurahan Tara-tara Tiga terletak di Kecamatan Tomohon Barat Kota Tomohon tepatnya dibawah kaki gunung lokon dan gunung kaseke.Masyarakat kelurahan tara-tara tiga memiliki mata pencarian rata-rata adalah petani $(85 \%)$ ini dapat dilihat dari kawasan perkebunan masyarakat yang ditanamami pohon kelapa, cengkeh, serta komoditi hortikutura lainya.Hasil pertanian tersebut turut meramaikan pasar tomohon yang menjadi pusat pemasaran,berdasarkan potensi yang ada dikelurahan tara-tara tiga memiliki berbagai bidang usaha dibidang pertanian peternakan perikanan dan perkebunanyang diolah secara kelompok maupun perorangan. Selain usaha dibidang pertanian, peternakan,perikanan dan perkebunan ada juga kelompok-kelompok social seperti duka, suka melakukan dibidang seni budaya yaitu kelompok maengket, zumawi, music kulintang, music bambu. Dibidang pendidikan kelurahan Tara-tara Tiga memiliki fasilitas pendidikan berupa TK, SD SMA sedangkan fasilitas keagamaan terdapat gedung gereja GMIM SILOAM, GMIM GLORIA, GPDI TIBERIAS. Dibidang ekonomi pertanian tara-tara tiga memiliki fasilitas gedung lumbung pangau,dan lantai seminar, juga dengan swadaya masyarakat, kelurahan telah menyediakan tanah untuk lokasi pengadaan pembangunan pasar tradisional.

\section{Letak Geografis}

Kelurahan Tara-tara Tiga merupakan salah satu kelurahan yang terletak di Kecamatan Tomohon Barat dengan letak geografis pada :

$01^{\circ} 19^{\prime} 00$ sampai dengan $01^{\circ} 21^{\prime} 32$ lintang utara

$124^{\circ} 44^{\prime} 10$ sampai dengan $124^{\circ} 46^{\prime} 50$ bujur timur

Luas wilayah : 722,21 Ha terbagi 7 lingkungan

\section{Batas-Batas Wilayah}

Adapun batas-batas wilayah Kelurahan

Tara-tara Tiga adalah:

1. Sebelah utara berbatasan dengan gunung kaseke dan gunung lokon

2. Sebelah selatan berbatasan dengan hutan lindung

3. Sebelah timur berbatasan dengan Kelurahaan Woloan Tiga dan Kelurahan Kayawu

4. Sebelah barat berbatasan dengan Tara-Tara dua.

\section{Struktur Organisasi P3A}

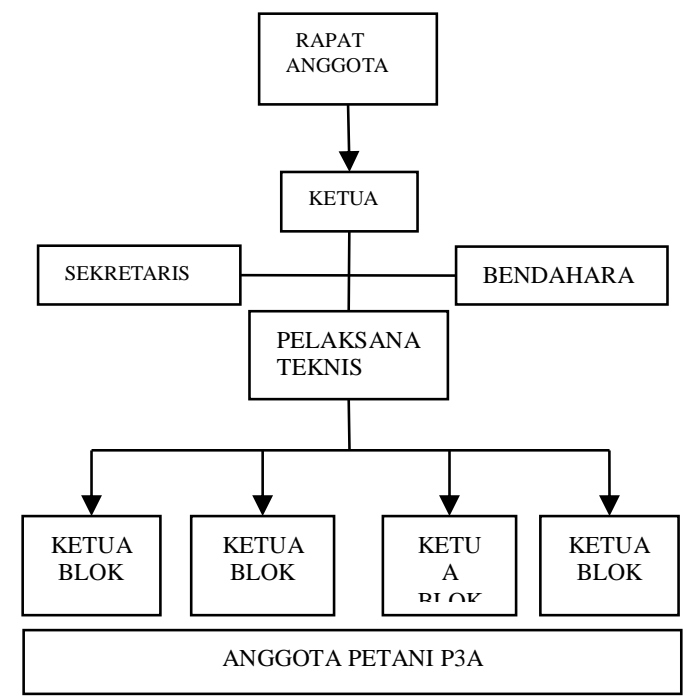




\section{Profil P3A Ketusaran}

P3A ketusaran merupakan, suatu organisasi kemasyarakatan yang mewadahi para petani yang berada di wilayah daerah irigasi tara-tara tiga kecamatan tomohon barat kota tomohon. Sebagian besar masyarakat petani yang tergabung dalam P3A merupakan, para petani yang menjadikan padi sebagai tanaman utama untuk dibudidayakan.Untuk menambah pendapatan rumah tangga, para petani ada yang melakukan diversifikasi usaha seperti perikanan, peternakan dan industri rumah tangga.Akan tetapi, sebagian besar petani masih menggantungkan hidupnya dari bertani padi atau menjadi buruh tani.P3A Ketusaran bertujuan untuk meningkatan kemampuan pengaturan, untuk pengelolaan jaringan irigasi agar perkumpulan petani pemakai air berpartisipasi dalam pengelolaan irigasi sesuai dengan kemampuannya.Peningkatan kemampuan untuk memperbaiki kinerja pengelolaan dan lembaga pengelola sumber daya air. Mencapai keberlanjutan dalam pendanaan atau iuran irigasi, dan Pengembangan kemampuan lokal yang berkelanjutan untuk peningkatan kemampuan yang berkesinambungan. P3A ketusaran dibentuk pada tahun (1995), dengan jumlah anggota 138 anggota P3A yang beralamat di kelurahan tara-tara tiga Kecamatan Tomohon Barat Kota Tomohon.Tujuan P3A ketusaran adalah menjadikan P3A ketusaran sebagai organisasi yang dapat meningkatan kesejahteraan petani pemakai air di kelurahan tara-tara tiga keamatan tomohon barat kota tomohon. P3A ketusaran kelurahan tara-tara tiga kecamatan tomohobn barat kota tomohon meliputi tujuh lingkungan. Luas areal lahan terairi daerah irigasi tara-tara tiga 25 hektar.

\section{Umur Responden \\ Karakteristik Responden}

Kemampuan bekerja atau melakukan aktifitas secara fisik bahkan cara berpikir seseorang sangat dipengaruhi oleh faktor umur. Demikian juga dengan para petani dalam pelakukan pekerjaannya, anggota yang memiliki umur muda tentunya memiiki kondisi fisik yang lebih kuat serta memiliki daya berpikir yang lebih kreatif dibandingkan yang berumur tua. Dari data primer yang diperoleh usia anggota antara 40 sampai 80 tahun.
Komposisi responden dalampenelitian ini disajikan pada Tabel 1.

Tabel 1. Distribusi Responden Menurut Umur Anggota P3A (Perkumpian Petani Pemakai Air)

\begin{tabular}{cccc}
\hline No & Umur & $\begin{array}{c}\text { Jumlah Responden } \\
\text { (orang) }\end{array}$ & $(\%)$ \\
\hline 1 & $40-45$ & 6 & 20,00 \\
2 & $46-50$ & 5 & 16,66 \\
3 & $51-55$ & 8 & 25,67 \\
4 & $56-60$ & 4 & 13,33 \\
5 & $61-65$ & 6 & 20,00 \\
6 & $>80$ & 1 & 3,33 \\
\hline & Jumlah & 30 & 100,00 \\
\hline
\end{tabular}

Tabel 1 menunjukan jumlah responden pada umur anggota P3A atau perkumpuan petani pemakai air. Umur 40-45 tahun menunjukan presentase yaitu sebanyan 6 responden (20\%) selanjutnya berada pada usia 46-50 tahun menunjukan presentase sebanyak 5 responden $(16,66 \%)$, pada usia 51-55 tahun menunjukan presentase sebanayak 8 responden $(13,33 \%)$, pada usia 56-60 tahun menunjukan presentase sebanyak 4 responden (20\%), pada usia 61-65 tahun menunjukan presentase sebanyak 6 responden $(20 \%)$ dan $>80$ tahun menunjukan presentase sebanyak 1 responden $(3,33 \%)$.

\section{Tingkat Pendidikan Responden}

Peranan pendidikan formal sangat penting dalam usaha meningkatakan kualitas seseorang karena berguna dalam pembangunan pribadi serta peningkatan intelektual dan wawasan seseorang.Berdasarkan hasil penelitian, tingkat pendidikan responden bervariasi mulai dari tingkat sekoah dasar (SD), SLTP, SMA, dan S1. Komposisi tingkat pendidikan responden dalam penelitian ini dapat di liahat pada Tabel 2.

Tabel 2.Pendidikan Responden

\begin{tabular}{cccc}
\hline No & $\begin{array}{c}\text { Jenjang } \\
\text { pendidikan }\end{array}$ & $\begin{array}{c}\text { Jumla responden } \\
\text { (orang) }\end{array}$ & $\begin{array}{c}\text { Presentase } \\
(\%)\end{array}$ \\
\hline 1 & SD & 4 & 13,33 \\
2 & SMP & 9 & 30,00 \\
3 & SMA & 14 & 46,66 \\
4 & SLTP & 1 & 3,33 \\
5 & S1 & 2 & 6,66 \\
\hline & Jumlah & 30 & 100,00 \\
\hline
\end{tabular}


Tabel 2 menunjukan responden menurut tingkat pendidikan anggota petani P3A atau perkumpulan petani pemakai air. SD ada 4 responden atau $(13,33 \%)$ SMP sebanyak 9 responden $(30 \%)$, SLTP ada 1 responden $(3,33)$, SMA sebanyak 14 responden $(46,66 \%)$, Dan $\mathrm{S} 1$ ada 2 responden $(6,66 \%)$.

Responden Berdasarkan Jenis Kelamin Anggota Petani P3A Atau Perkumpulan Petani Pemakai Air Ketusaran

Menunjukan bahwa jumah responden semuanya hanya bejenis kelamin laki-laki dengan 30 orang $(100 \%)$.

\section{Partisipasi Fisik}

Melakukan Perbaikan Banguan yang Rusak

Dalam hal ini adalah sebarapa aktif anggota terlibat dalam tahap memperbaiki beton yang rusak, dalam penelitian ini diukur dalam setahun dapat dilihat pada Tabel 3.

Tabel 3. Melakukan Perbaikan Bangunan Irigasi yang

\begin{tabular}{cccccc}
\hline \multicolumn{2}{c}{ Rusak } & & & & \\
\hline Partisipasi & $\begin{array}{c}\text { Alternat } \\
\text { ifSkor }\end{array}$ & $\begin{array}{c}\text { Jumlah } \\
\text { Responden } \\
\text { (orang) }\end{array}$ & $(\%)$ & $\begin{array}{c}\text { Total } \\
\text { Skor }\end{array}$ \\
\hline 1 & Aktif & 3 & 19 & 63,33 & 57 \\
2 & Kurang Aktif & 2 & 9 & 33,33 & 22 \\
3 & Tidak Aktif & 1 & 1 & 333 & 1 \\
\hline & Jumlah & & 30 & $\begin{array}{c}100,0 \\
0\end{array}$ & 79 \\
\hline
\end{tabular}

Hasil peneitian ini menunjukan bahwa 19 responden (63,33\%)memilih aktif. Anggota yang memilih aktif adalah anggota yang sadar akan statustnya sebagai pengurus irigasi ,dan anggota yang menginginkan terciptanya kekompakan sesama anggota dalam melaksanakan kegiatan pertanian, 10 responden $(33,33 \%)$ memilih kurang aktif dalam memperbaiki beton yang rusak adalah anggota yang berpartisipasi tetapi tidak rutin dalam memperbaiki beton yang rusak, dan 1 responden $(3,33)$ memilih tidak aktif hal ini dikarenakan berbagai kesibukan.

\section{Membersihkan saluaran dan bangunan dari tanaman liar}

Dalam hal ini adalah seberapa aktif anggota P3A dalam memelihara jaringan irigasi seperti membersihkan saluran dan bangunan dari tanaman liar, dalam peneitian ini diukur dalan setahun dapat diihat pada Tabel 4 .

Tabel 4. Membesihkan saluran dan bangunan dari tanaman liar

\begin{tabular}{cccccc}
\hline No & $\begin{array}{c}\text { Tingkat } \\
\text { Partisipasi }\end{array}$ & $\begin{array}{c}\text { Alternatife } \\
\text { Skor }\end{array}$ & $\begin{array}{c}\text { Jumlah } \\
\text { Responden } \\
\text { (orang) }\end{array}$ & (\%) & $\begin{array}{c}\text { Total } \\
\text { Skor }\end{array}$ \\
\hline 1 & Aktif & 3 & 23 & 76,66 & 69 \\
2 & Kurang & 2 & 7 & 23,33 & 17 \\
& Aktif & & & & \\
3 & Tidak & 1 & - & - & - \\
& Aktif & & 30 & 100,00 & 83 \\
\hline & Jumlah & & 3 & &
\end{tabular}

Hasil penelitian ini menunjukan bahwa 23 responden $(76,66 \%)$ memilih aktif , anggota yang memilih aktif dalam memebersihkan bangunan dari tanaman liar adalah anggota yang mengininkan terciptanya kekompakan dan kerja sama dalam pemeliharaan jaringan irigasi, 7 responden $(23,33 \%)$ memilih kurang aktif adalah anggota yang berpartisipasi tetapi tidak rutin dalam membersihkan bngunan dari tanaman liar.

\section{Membesihkan saluran dan bangunan dari sampah dan kotoran}

Dalam hal ini adalah seberapa aktif anggota P3A dalam membersihkan saluran dan bangunan dari sampah dan kotoran.Dalam hal ini bukan hanya sekedar meberisihkan saluran tetapi juga berperan aktif dalam pemeliharaan jaringan irigasi, penelitian ini diukur dalam setahun dapat dilihat Tabel 5.

Tabel 5. Membersihkan saluaran dan bangunan dari sampah dan kotoran

\begin{tabular}{lccccc}
\hline No & $\begin{array}{c}\text { Tingkat } \\
\text { Partisipasi }\end{array}$ & $\begin{array}{c}\text { Alternatife } \\
\text { Skor }\end{array}$ & $\begin{array}{c}\text { Jumlah } \\
\text { Responden } \\
\text { (orang) }\end{array}$ & (\%) & TotalSkor \\
\hline 1 & Aktif & 3 & 23 & 76,66 & 69 \\
2 & $\begin{array}{c}\text { Kurang } \\
\text { Aktif }\end{array}$ & 2 & 7 & 23,33 & 14 \\
3 & $\begin{array}{c}\text { Tidak Aktif } \\
\text { Jumlah }\end{array}$ & 1 & - & - & - \\
\hline
\end{tabular}

Tabel 5 menunjukan bahwa 23 responden $(76,66 \%)$ memilih aktif dalam membersihkan saluran dari sampah dan kotoran, adalah anggota yang mengininkan terciptanya kekompakan dan kerjasama dalam pemeliharaan jaringan irigasi, 8 responden $(23,33 \%)$ memilih kurang aktif adalah anggota 
yang berpartisipasi tetapi tidak rutin dalam membersihkan saluran irigasi tersebut.

\section{Partisipasi Non Fisik}

\section{Diwujudkan rapat}

Dalam hal ini adalah seberapa aktif anggota P3A mendirikan rapat dalam keatifan kegiatan P3A atau perkumpulan petani pemakai air, dalam penelitian ini diukur dalam setahun dapat di lihat Tabel 6.

\begin{tabular}{cccccc}
\multicolumn{2}{c}{ Tabel 6. Diwujudkan rapat } \\
\hline No & $\begin{array}{c}\text { Tingkat } \\
\text { Partisipasi }\end{array}$ & $\begin{array}{c}\text { Alternatife } \\
\text { Skor }\end{array}$ & $\begin{array}{c}\text { Jumlah } \\
\text { Responden } \\
\text { (orang) }\end{array}$ & $(\%)$ & $\begin{array}{c}\text { Total } \\
\text { Skor }\end{array}$ \\
\hline 1 & Aktif & 3 & 11 & 36,67 & 33 \\
2 & Kurang & 2 & 19 & 63,33 & 38 \\
& Aktif & & - & - & - \\
3 & Tidak Aktif & 1 & 30 & 100,00 & 71 \\
\hline \multicolumn{7}{c}{ Jumlah } & & & &
\end{tabular}

Tabel 6 menunjukan bahwa 11 responden $(36,67 \%)$ memilih aktif dalam diwujudkan rapat adalah anggota yang sadar akan statusnya sebagai anggota P3A untuk pemeliharaan jaringan irigasi yang menginginkan kekompakan dan kerjasama, 19 responen $(63,33 \%)$ memilih kurang aktif dalam diwujudkan rapat, anggota yang berpartisipasi tetapi tidak rutin dalam diwujudkan rapat.

\section{Waktu rapat (kehadiran dalam rapat)}

Dalam hal ini adalah seberapa aktif anggota P3A hadir diwaktu rapat dalam pelaksanaan pemeliharaan jaringan irigasi, dalam hal ini bukan hanya sekedar rapat tetapi juga akitif dalam kehadiran anggota P3A, dan penelitian ini diukur dalam setahundapat dilihat pada Tabel 7.

\begin{tabular}{|c|c|c|c|c|c|}
\hline No & $\begin{array}{c}\text { Tingkat } \\
\text { Partisipasi }\end{array}$ & $\begin{array}{l}\text { Alternatife } \\
\text { Skor }\end{array}$ & $\begin{array}{l}\text { Jumlah } \\
\text { Responden } \\
\text { (orang) }\end{array}$ & $(\%)$ & $\begin{array}{l}\text { Total } \\
\text { Skor }\end{array}$ \\
\hline 1 & Aktif & 3 & 14 & 46,67 & 42 \\
\hline 2 & $\begin{array}{l}\text { Kurang } \\
\text { Aktif }\end{array}$ & 2 & 16 & 53,33 & 32 \\
\hline 3 & $\begin{array}{l}\text { Tidak } \\
\text { Aktif }\end{array}$ & 1 & - & - & \\
\hline & Jumlah & & 30 & $\mathbf{1 0 0 , 0 0}$ & 74 \\
\hline
\end{tabular}

Tabel 7 menunjukan bahwa 14 responden $(46,67 \%)$ memilih aktif dalam kehadiran rapat adalah anggota yang sadar akan statusnya dan kewajiban mnghadiri rapat P3A, dan anggota yang menginginkan terciptanya kerjasama dan kekompakan dalam menjlankan kegiatan P3A untuk pemeliharaan jaringan irigasi, 16 reponden $(53,33 \%)$ memiih kurang aktif adalah anggota yang berpartisipassi tetapi tidak rutin dalam kehadiran rapat.

\section{Sumbangan gagasan (saran) (Pendapat) (Hasil Rapat)}

Dalam hal ini adalah seberapa aktif anggota P3A dalam mnyumbangkan pendapat saran dan hasil rapat, dalam hal ini bukan hanya sekedar sumbangan pendapat dan saran tetapi berperan aktif dalam kegiatan rapat, dalam penelitian ini diukur dalam setahun dapat dilihat pada Tabel 8.

Tabel 8. Dalam sumbangan gagasan (saran, pendapat, hasil

\begin{tabular}{|c|c|c|c|c|c|}
\hline No & $\begin{array}{c}\text { Tingkat } \\
\text { Partisipasi }\end{array}$ & $\begin{array}{c}\text { Alternatif } \\
\text { Skor }\end{array}$ & $\begin{array}{c}\text { Jumlah } \\
\text { Responden } \\
\text { (orang) }\end{array}$ & $(\%)$ & $\begin{array}{l}\text { Total } \\
\text { Skor }\end{array}$ \\
\hline 1 & Aktif & 3 & 10 & 33.33 & 30 \\
\hline 2 & $\begin{array}{c}\text { Kurang } \\
\text { Aktif }\end{array}$ & 2 & 16 & 53,33 & 32 \\
\hline 3 & $\begin{array}{l}\text { Tidak } \\
\text { Aktif }\end{array}$ & 1 & 4 & 13,33 & 4 \\
\hline & Jumlah & & 30 & 100,00 & 66 \\
\hline
\end{tabular}

Tabel 8 menunjukan bahwa 10 reponden $(33,33 \%)$ memiih aktif anggota yang memilih aktif adalah anggota yang sadar akan statusnya dan kewajibaan sebagai anggota petani P3A dalam pemeliharaan jaringan iriagsi, yang menginginkan terciptanya kerjasama dan kekompakan sesama anggota P3A dalam kegiatan pertanian, 16 responden $(53,33 \%)$ memilih kuarang aktif adalah anggota yang berpaertisipasi tetpi tidak rutin dalam hal smubangan gagasan, dan 4 responden $(13,33 \%)$ memilih tidak aktif dalam rapat sumbangan gagasan atau membrikan saran, pendapat dan sebgainya, hal ini dikrenakan berbagai kesibukan.

\section{Rapat dengan pengurus P3A}

Dalam hal ini adalah seberapa aktif anggota terlibat rapat dengan anggota dalam hal ini bukan hanya sekedar rapat tetapi bjuga berperak aktif dalam keterlibaan pengurus dan anggota dalam pemeliharaan jaringan irigasi, 
dalam penelitian ini diukur dalam setahun dapat dilihat pada Tabel 9.

\begin{tabular}{|c|c|c|c|c|c|}
\hline No & $\begin{array}{c}\text { Tingkat } \\
\text { Partisipasi }\end{array}$ & $\begin{array}{c}\text { Alternatife } \\
\text { Skor }\end{array}$ & $\begin{array}{l}\text { Jumlah } \\
\text { Responden } \\
\text { (orang) }\end{array}$ & (\%) & $\begin{array}{l}\text { Total } \\
\text { Skor }\end{array}$ \\
\hline 1 & Aktif & 3 & 13 & 43,33 & 39 \\
\hline 2 & $\begin{array}{l}\text { Kurang } \\
\text { Aktif }\end{array}$ & 2 & 17 & 56,67 & 34 \\
\hline 3 & $\begin{array}{l}\text { Tidak } \\
\text { Aktif }\end{array}$ & 1 & - & - & - \\
\hline & Jumlah & & 30 & 100,00 & 73 \\
\hline
\end{tabular}

Tabel 9 menunjukan bahawa 13 responden $(43,33 \%)$ memilih aktif anggota yang memilih aktif adalah anggota yang sadar akan statusnya sebagai pengurus, pengurus yang menginginkan kerjasama dan kekompakan dengan anggota dalam melaksanakan pemeliharaan jaringan irigasi agar berjalan dengan baik, 17 responden $(56,67 \%)$ memilih kurang aktif adalah anggota yang berpartisipasi tetapi tidak rutin dalam hal rapat dengan penguturus $\mathrm{P} 3 \mathrm{~A}$.

\section{Penyumbangan dan mengurus iuran} pembiayaan saluran irigasi 12 kali sekali tahun

Dalam hal ini adalah seberapa aktif anggota memberikan iuran wajib yang dikumpul sekali dalam perbulan untuk dipakai berbagai kegiatan P3A seperi memperbaiki saluran dan beton yang rusak ringan,dalam penelitian ini keaktifan di ukur selama setahun, keaktifan penyumbangan dan mengurus iuran pembiayaan saluran irigasi dapat dilihat pada Tabel 10.

\begin{tabular}{cccccc} 
Tabel & 10. & $\begin{array}{c}\text { Penyumbangan } \\
\text { pembiayaan saluran irigasi }\end{array}$ & $\begin{array}{c}\text { dan mengurus } \\
\text { iuran }\end{array}$ \\
\hline No & $\begin{array}{c}\text { Tingkat } \\
\text { Partisipasi }\end{array}$ & $\begin{array}{c}\text { Alternatif } \\
\text { skor }\end{array}$ & $\begin{array}{c}\text { Jumlah } \\
\text { Responden } \\
\text { (orang) }\end{array}$ & $(\%)$ & $\begin{array}{c}\text { Total } \\
\text { Skor }\end{array}$ \\
\hline 1 & Aktif & 3 & 2 & 6,67 & 6 \\
2 & $\begin{array}{c}\text { Kurang } \\
\text { Aktif }\end{array}$ & 2 & 13 & 43,33 & 26 \\
3 & Tidak Aktif & 1 & 15 & 50,00 & 14 \\
\hline \multicolumn{7}{c}{ Jumlah } & & 30 & 10,00 & 47 \\
\hline
\end{tabular}

Tabel 10 menunjukan bahwa 2 responden $(6,67 \%)$ memilih aktif adalah anggota yang sadar akan kewajiban dan statusnya sebagai anggota maupun pengurus P3A, anggota dan pengurus menginginkan aktif membayar iuran tersebut yang telah disepakati bersama karena untuk kepentingan bersama dalam melaksnakan kegiatan P3A, 13 responden $(43,33 \%)$ memilih kurang aktif adalah anggota yang berpartisipasi tetpai kurang dalm hal mengumpulkan iuran untuk menunjang kegiatan $\mathrm{P} 3 \mathrm{~A}, 15$ reponden $(50 \%)$ memiih tidak aktif adalah anggota yang sibuk dengan berbagai kesibukan lainnya.

\section{Rekaptulasi Data}

Berdasarkan Data yang di peroleh pada tiap-tiap Tabel kategori variabel di atas, kita dapat melhat rekapitulasi data Keseluruhan pada Tabel 11.

\begin{tabular}{llcc} 
Tabel 11. Rekaptulasi Data \\
\hline No & \multicolumn{1}{c}{ Variabel } & Skor & Persentase \% \\
\hline 1 & $\begin{array}{l}\text { Keaktifan Melakukan } \\
\text { Perbaikan Beton Yang Rusak }\end{array}$ & 73 & 12,67 \\
2 & $\begin{array}{l}\text { Keaktifan Membersihkan } \\
\text { Saluran dan Pembangunan } \\
\text { dari Tanaman Liar }\end{array}$ & 83 & 14,40 \\
3 & $\begin{array}{l}\text { Keaktifan Membersihkan } \\
\text { Saluran dan Bangunan dari }\end{array}$ & 83 & 14.40 \\
& $\begin{array}{l}\text { Sampah dan Kotoran } \\
\text { Keaktifan Anggota } \\
\text { Diwujudkan Rapat }\end{array}$ & 71 & 12,32 \\
5 & $\begin{array}{l}\text { Keaktifan Waktu Rapat( } \\
\text { Kehadiran Rapat) Sumbangan } \\
6\end{array}$ & $\begin{array}{l}\text { Keaktifan Dalam Sumban } \\
\text { Gagasan (Saran,Pendapat, }\end{array}$ & 12,48 \\
7 & $\begin{array}{l}\text { Hasil Rapat) Keaktifan Anggota Rapat } \\
\text { Dengan Pengurus P3A }\end{array}$ & 73 & 11,45 \\
8 & $\begin{array}{l}\text { Keaktifan Penyumbngan dan } \\
\text { Mengurus Iuran Pembiayaan } \\
\text { Irigasi 47 }\end{array}$ & 8,15 \\
\hline \multicolumn{1}{c}{ Jumlah } & 576 & 100,00 \\
\hline
\end{tabular}

Tabel 11 menunjukan bahwa, pada variabel pertama yaitu keaktifan melakukan perbaikan beton mendapatakan skor 73 $(12,67 \%)$, dan pada variabel kedua yaitu keaktifan membersihkan saluran dan bangunan dari tanaman liar mendapatkan skor 83 $(14,40 \%)$, selanjutnya pada variabel ketiga keaktifan membersihkan saluran dan bangunan dari sampah dan kotoran mendapatkan skor 83 $(14,40 \%)$, pada variabel keempat yaitu keaktifan anggota diwujudkan rapat mendapatakan skor $71(12,32 \%)$, selanjutnya pada variabel kelima yaitu keaktifan waktu rapat (Keahadiran dalam Rapat) mendapatkan $74(12,84 \%)$, pada variabel keenam yaitu keaktifan dalam sumbangan gagasan (saran, pendapat dan hasil rapat) mendapatkan skor 66(11,45\%), selanjutnya pada variabel ketuju yaitu keaktifan anggota rapat dengan pengurus P3A mendapatkan skor 73(12,67\%), dan yang 
terakhir variabel kedelapan yaitu keaktifan penyumbangan dan mengurus iuran pembiayaan irigasi mendapatkan skor 47(8,15\%). Pendapat Penilaian partisipasi anggota petani $\mathrm{P} 3 \mathrm{~A}$ dalam pemelihraan jaringan irigasi berdasarkan skor dari masing-masing indicator partisipasi anggota P3A, sebagai berikut :

Jumlah skor : 17 - $24=$ Aktif

Jumlah skor: $9-16=$ Kurang Aktif

Jumlah skor : $0-8=$ Tidak Aktif

Kemudian diambil penilaian aktif dan tidak aktifnya parisipasi dalam pemeliharaan jaringan irigasi sebagai berikut:

Jumlah skor : $481-720=$ Aktif

Jumlah skor : $31-480=$ Kurang Aktif

Jumlah skor : $0-30=$ Tidak Aktif

Berdasarkan hasil analisis deskriptif maka dapat diketahui bahwa angka indeks partisipasi anggota petani P3A ketusaran tergolong tinggi. Kesimpulan secara keseluruhan dari penelitian ini tergambar dalam rekaptulasi jumlah skor partisipasi anggota petani P3A ketusaran, partisipasi pada kegiatan lainya smuanya tergolong tinggi kecuali keaktifan dalam penyumbangan dan pengurusan iuran pembiayaan irigasi yang tergolong rendah.

\section{KESIMPULAN DAN SARAN}

\section{Kesimpulan}

Dalam penelitian ini dapat dilihat Partisipasi Anggota P3A dalam Pemeliharaan Jaringan Irigasi di Kelurahan Tara-tara Tiga Kecamatan Tomohon Barat Kota Tomohon tertinggi yaitu, dalam membersihkan saluran dan bangunan dari tanaman liar, kedua dalam membersihkan saluaran dan bangunan dari sampah dan kotoran, ketiga dalam melakukan perbaikan banguan yang rusak, keempat dalam waktu rapat (kehadiran dalam rapat), kelima Anggota diwujudkan rapat, keenam yaitu dalam sumbangan gagasan(saran, pendapat, hasil rapat), ketujuh rapat dengan pengurus $\mathrm{P} 3 \mathrm{~A}$ dan yang terendah penyumbangan yakni anggota P3A dalam pemeliharaan jaringan irigasi, kurang berpartisipasi dalam hal penyumbangan dan mengurus iuran pembiayaan saluran irigasi. Dapat disimpulkan secara keseluruhan bahawa Partisipasi Anggota P3A dalam Pemeliharaan
Jaringan Irigasi di Kelurahan Tara-tara Tiga Kecamatan Tomohon Barat Kota Tomohon tergolong tinggi

\section{Saran}

Bagi anggota P3A ketusaran agar lebih meningkatkan keaktifan dalam berpartisipasi dengan sumbangan pembiayaan iuran irigasi, karena hal tersebut merupakan pelaku utama dalam pembangunan irigasi agar dapat meningkatkan kesejahteraan petani, dan pemerintah hendaknya memperhatikan apa yang menjadi kebtuhan dari anggota P3A "Ketusaran" untuk mengembangkan P3A pada umumnya.

\section{DAFTAR PUSAKA}

Anonimous, 2010. Pedoman Pemberdayaan Petani Pemakai Air (P3A). Dikutip dari perkumpulan petani pemakai air.Pada tanggal 3 Agustus 2010.

Azwar Wahirudin, 2013. Oprasi Dan Pemeliharaan Jaringan Irigasi Daerah Irigasi Cipuspa Desa Cicukang Kecamatan Purabaya Kaupaten Suka Bumi. Jurnal Universitas Pendidikan Indonesia.

Afrianti, N. 2011. Analisis partisipasi petanidalam pengelolaan irigasi di daerah irigasi Limau Manis Kota Padang Sumatera Barat. (Tesis). Jurusan Agronomi Fakultas Pertanian. Universitas Andalas.Padang

Hidayat dan Suroso, 2005.Perkembangan Kinerja Perkumpulan Petani Pemakai Air di Kabupaten Banyumas Studi Kasus Daerah Irigasi Andongbang, Banjaran dan Tajum. Jurnal Pembangunan Pedesaan (Terakreditasi), Lembaga Penelitian UNSOED, Purwokerto.

Nyoman sumaryadi, 2010. Sosiologi Pemerintahan dari Perspektif Pelayanan, Pemberdayaan, Interaksi, dan Sistem Kepemimpinan Pemerintahan Indonesia. Bogor: Ghalia Indonesia. 
Novi Arianti, 2011.Analisis Partisipasi Petani Dalam Pengelolaan Irigasi Di Daerah Irigasi Limau Manis Kota Padang Sumatra Barat.Skripsi Fakultas Pertanian Universitas Andalas Padang.

PartoWijoto, 2004. Irigasi di Indonesia : Dinamika KelembagaanPetani. LP3ES. Hlm. 307-308.

Paingga Rukmana DB, 2013. Pengaruh Patisipasi Anggaran dan Asimetri Informasi Terhadap TimbulnyaProgram Studi Akuntansi. Jurnal Universitas Negeri Padang.

Suluh Jatmiko, 2007 Kajian Pemeliharaan Jaringan Irigasi Daerah Irigasi (D.I) Tempurun Di Kabupaten Blora.Skripsi Fakultas Teknik Universitas Muhammadiyah Surakarta.

Sarwan, 2004, Konsepsi Pengembangan Program Operasi Pemeliharaan Irigasi, Direktorat Jendral Sumber Daya Air Departemen Pemukiman dan Prasarana,Wilayah Jakarta.
Sumaryanto Tamrin, 2006. Evaluasi kinerja Oprasi dan Pemeliharaan Jaringan.Irigasi dan upaya perbaikannya.

Sunarti, 2003. Partisipasi Masyarakat Dalam Pembangunan Perumahan Secara Berkelompok Dalam Tata Loka. Jurnal Ilmiah Perencanaan wilayah dan Kota, Biro Penerbit Jurusan Perencanaan Wilayah dan Kota, FaklutasTeknik Universitas Diponegoro, Semarang.

Tuti Yuliani, 2003. Kajian Tingkat Partisipasi Dalam Operasi Dan Pemeliharaan Untuk Perkumpulan Petani Pemakai Ari (P3A) Di Daerah Irigasi Boro.Skripsi. Kabupaten Purworejo. Unieritas Diponegoro Semarang.

Wiguna, P. P. K. 2008. Ketersediaan Air Untuk Irigasi di DAS Kayangan Kabupaten Kulon Progo. Skripsi. Fakultas Geografi, Universitas Gadjah Mada, Yogyakarta 